\title{
EFFECT OF REACTIVE HYPEREMIA ON FOREARM VEIN AREA: A BLINDED STUDY
}

Authors: Heather L Mollison MD, Rajesh H Patel MD, William PS McKay MD, Stefan Kriegler MBChB MMed

Affiliations: Departments of Anesthesia and Radiology, University of Saskatchewan, Royal University Hospital, 103 Hospital Drive, Saskatoon, Saskatchewan, S7N 0W8

\section{INTRODUCTION}

Reactive hyperemia is a transient increase in organ or limb blood flow following a brief period of ischemia. The purpose of this study was to determine the effect of reactive hyperemia on human forearm vein area.

\section{METHODS}

Following Biomedical Research Ethics Board approval, twenty consenting adult subjects were studied. Exclusion criteria included: hypertension, neural or vascular limb disorders, pregnancy, and allergy to ultrasound gel. Ischemia was achieved with a tourniquet inflated on the upper arm to 200 torr, or to 25 torr for non-ischemic comparison.

Based on the results of our pilot study, all subjects received the same six treatments comparing 1, 2 and 3 minute periods of ischemia and non-ischemia. After each treatment, serial ultrasound scans of a predetermined forearm vein were recorded. All ultrasound scans were read by a radiologist blinded to the treatment.

\section{RESULTS}

The mean vein area $\left(\mathrm{mm}^{2}\right)$ increased from $8.22+/-3.09$ to $10.77+/-3.50$ after 1 minute of ischemia, from $8.31+/-2.78$ to $10.61+/-2.77$ after 2 minutes of ischemia, and from $8.39+/-3.34$ to $10.94+/-3.46$ after 3 minutes of ischemia $(\mathrm{P}<0.05$ for all $)$.

\section{DISCUSSION}

Numerous studies have demonstrated the effect of reactive hyperemia on the arterial system in human limbs. ${ }^{1,2}$ However, the effect of reactive hyperemia on venous area has not been well studied. ${ }^{3}$ This study confirms the results obtained from our pilot study. Reactive hyperemia increases forearm vein area. The placement of peripheral intravenous catheters may be facilitated by using reactive hyperemia to dilate the veins.

\section{REFERENCES}

1 J Cardiovasc Pharmacol. 36:640-648.

2 Am J Cardiol. 85:1071-1076.

3 J Vasc Surg. 29:1065-1070. 